\title{
The Fabrication of a Bifunctional Oxygen GDE without Carbon Components for Alkaline Secondary Batteries
}

\author{
Stephen W.T. Price ${ }^{\mathrm{a}}$ and Stephen J. Thompson ${ }^{\mathrm{a}}$, Xiaohong Li ${ }^{\mathrm{b}}$, Scott F. Gorman ${ }^{\mathrm{b}}$, \\ Derek Pletcher ${ }^{\mathrm{a}}$, Andrea E. Russell ${ }^{\mathrm{a}}$, Frank C. Walsh ${ }^{\mathrm{b}}$, Richard G.A. Wills ${ }^{\mathrm{b}}$, \\ ${ }^{\mathrm{a}}$ Chemistry, University of Southampton, Southampton, SO17 1BJ, UK \\ ${ }^{\mathrm{b}}$ Energy Technology Group, University of Southampton, Southampton, SO17 1BJ, UK
}

\begin{abstract}
The fabrication of a gas diffusion electrode (GDE) without carbon components is described; it is therefore suitable for use as a bifunctional oxygen electrode in alkaline secondary batteries. The electrode is fabricated in two stages (a) the formation of a PTFEbonded nickel powder layer on a nickel foam substrate and (b) the deposition of a $\mathrm{NiCo}_{2} \mathrm{O}_{4}$ spinel electrocatalyst layer by dip coating in a nitrate solution and thermal decomposition. The influence of modifications to the procedure on the performance of the GDEs in $8 \mathrm{M}$ $\mathrm{NaOH}$ at $333 \mathrm{~K}$ is described. The GDEs can support current densities up to $100 \mathrm{~mA} \mathrm{~cm}^{-2}$ with state-of-the-art overpotentials for both oxygen evolution and oxygen reduction. Stable performance during 100 successive, 1 hour oxygen reduction/evolution cycles at a current density of $50 \mathrm{~mA} \mathrm{~cm}^{-2}$ has been achieved.
\end{abstract}

Keywords: Carbon free gas diffusion electrode (GDE), bifunctional electrode, oxygen evolution/reduction. 


\section{Introduction}

A successful renewable energy economy will require energy storage to manage the time differences between generation and customer demand. One solution is offered by flow batteries [1-3] although none of the systems extensively studied offer ideal behaviour and economics. Secondary metal/air batteries, particularly zinc/air [4-6], merit development. In a zinc/air battery, the electrode reactions are:

negative electrode

$$
\mathrm{Zn}(\mathrm{OH})_{4}{ }^{2-}+2 \mathrm{e}^{-} \underset{\text { discharge }}{\stackrel{\text { charge }}{\rightleftarrows}} \mathrm{Zn}+4 \mathrm{OH}^{-}
$$

positive electrode

$$
4 \mathrm{OH}^{-}-4 \mathrm{e}^{-} \underset{\text { discharge }}{\stackrel{\text { charge }}{\rightleftarrows}} \mathrm{O}_{2}+2 \mathrm{H}_{2} \mathrm{O}
$$

battery

$$
2 \mathrm{Zn}(\mathrm{OH})_{4}{ }^{2-} \underset{\text { discharge }}{\stackrel{\text { charge }}{\rightleftarrows}} \quad 2 \mathrm{Zn}+\mathrm{O}_{2}+4 \mathrm{OH}^{-}+2 \mathrm{H}_{2} \mathrm{O}
$$

The battery has a thermodynamic potential of $\sim 1.65 \mathrm{~V}$. Clearly, one requirement is a bifunctional oxygen electrode, ie. an electrode that supports both oxygen evolution and reduction.

A recent communication [7] described a novel procedure for fabrication of a bifunctional oxygen electrode for alkaline secondary metal air batteries. In this procedure, a nickel metal powder/PTFE gas diffusion electrode (GDE) is preformed within a nickel foam prior to the deposition of a catalyst layer by dip coating and thermal treatment. This paper now reports the influence of the numerous parameters in the fabrication procedure on the performance of these electrodes.

While the choice of electrocatalyst is clearly important, it needs to be recognised that a gas diffusion electrode suitable as a bifunctional oxygen electrode must have a series of properties:

- both oxygen evolution and reduction must be possible with 'low' overpotentials.

- it must act as an effective barrier between the electrolyte and the gas phase, not allowing leakage in either direction. 
- in order to permit a high rate of discharge it is essential to have a high flux of oxygen from the gas phase to the catalyst sites that are likely to be situated close to the electrode/electrolyte interface.

- during charge, the oxygen gas must be effectively released, ideally into the gas phase away from the interelectrode gap where the gas bubbles will add to the IR drop.

- the GDE must have a low resistance network for passage of current between the catalyst centres and the external contacts to the electrode.

- the GDE must maintain these characteristics during extensive charge/discharge cycling at practical current densities, preferably up to $100 \mathrm{~mA} \mathrm{~cm}^{-2}$.

- the GDE must also have the physical and mechanical properties that allow its scale-up and implementation in flow cells with electrode areas up to $1 \mathrm{~m}^{2}$.

The design of the GDEs was based on a number of prior studies.

(a) Nickel cobalt spinel, $\mathrm{NiCo}_{2} \mathrm{O}_{4}$ was selected as the electrocatalyst [8-14]. Preliminary experiments showed that it gave overpotentials for both oxygen evolution and reduction that were at least comparable to other electrocatalysts including precious metals. However, it had the advantage that it was readily prepared and this could be achieved at a relatively low temperature where other components of the GDEs were stable; this is essential for the approach used in this paper.

(b) Carbon materials within the GDEs (powder and paper) were avoided since the literature has concluded that carbons corrode under the forcing conditions of oxygen evolution [16-19] and this was also our experience.

(c) The polymer selected as binder in the GDEs was PTFE. Cation conducting polymers were considered unsuitable because of the key role of hydroxide ion in the battery chemistry and no anion conducting polymers with the appropriate properties have been located.

The medium chosen was $8 \mathrm{M} \mathrm{NaOH}$ at $333 \mathrm{~K}$. Sodium hydroxide is substantially cheaper than potassium hydroxide and also allows a significant increase in the zincate concentration $(1.2 \mathrm{M}$ cf $0.5 \mathrm{M})$. The use of the elevated temperature leads to large decreases in the overpotentials for the electrode reactions as well as increasing the solubility of the sodium zincate; it is also a typical steady state temperature for a large scale electrolysis cell system. 


\section{Experimental}

\subsection{Chemicals}

Nickel powder $(2-10 \mu \mathrm{m}$ particle size determined by SEM) was supplied by Huizhou Wallyking Battery Ltd, China. Two sources of nickel foam were used - Goodfellow Metals (thickness $1.9 \mathrm{~mm}, 20$ pores/cm) and Changsha Lyrun New Material Co. Ltd (thickness $1.6 \mathrm{~mm}, 43$ pores/cm). Nickel nitrate (Aldrich, 99.999\%), cobalt(II) nitrate (Aldrich, $\geq 98 \%$ ), sodium hydroxide (Fisher, 97\%), polytetrafluoroethylene (PTFE, Aldrich, $60 \mathrm{wt} \%$ dispersion in $\mathrm{H}_{2} \mathrm{O}$ ) were used as received.

The nickel cobalt spinel, $\mathrm{NiCo}_{2} \mathrm{O}_{4}$, powder was prepared by a thermal decomposition procedure. $\mathrm{Ni}\left(\mathrm{NO}_{3}\right)_{2} \cdot 6 \mathrm{H}_{2} \mathrm{O}(14.54 \mathrm{~g})$ and $\mathrm{Co}\left(\mathrm{NO}_{3}\right)_{2} \cdot 6 \mathrm{H}_{2} \mathrm{O}(29.1 \mathrm{~g})$ were dissolved in methanol (100 $\mathrm{cm}^{3}$ ) and heated at $338 \mathrm{~K}$ in fume cupboard to evaporate solvent. The dried powder sample was placed into the Carbolite furnace in air at $648 \mathrm{~K}$ for $20 \mathrm{hrs}$. The resulting black powder was characterized by SEM, TEM, EDAX, XRD and BET analysis and a further paper [ref] will discuss the data in detail as well as comparing spinel powders from several preparation procedures. Here, we note that samples from repetition of the preparation led to materials with well-defined XRD patterns characteristic of a spinel structure, a ratio of Ni:Co close to 1:2 (determined by both EDAX and elemental analysis) and BET surface area of $\sim 10 \mathrm{~m}^{2} \mathrm{~g}^{-1}$.

\subsection{Preparation of Gas Diffusion Electrodes}

The procedure for making the bifunctional oxygen gas diffusion electrodes (GDEs) is illustrated with a particular example. The first stage led to a porous nickel powder/PTFE layer on nickel foam. The nickel foam (discs, diameter $12 \mathrm{~mm}$ ) was ultrasonicated in acetone for 20 minutes, acid etched in $1 \mathrm{M} \mathrm{HCl}$ at $353 \mathrm{~K}$ for $\sim 1$ hour and then washed with water and ultrasonicated in water for 15 minutes. Nickel powder $(150 \mathrm{mg})$ and $60 \%$ PTFE solution (75 $\mathrm{mg}$ ) were mixed with isopropanol $\left(0.5 \mathrm{~cm}^{3}\right)$ and water $\left(0.5 \mathrm{~cm}^{3}\right)$. The paste was then ultrasonicated for 20 minutes and homogenised for 4 minutes to form an ink before drying to a paste with a ratio of Ni:PTFE of 10:3. The Ni/PTFE paste (200 mg wet weight $\sim 120-150$ mg dry weight) was spread uniformly over the Ni foam disc and pressed in a Specac hydraulic press at $1.5 \mathrm{kN} \mathrm{cm}^{-2}$ and $298 \mathrm{~K}$ for $30 \mathrm{~s}$. The second step was to form the catalyst layer. The nickel powder/PTFE coated nickel foam was soaked in a solution containing $1 \mathrm{M}$ $\mathrm{Ni}\left(\mathrm{NO}_{3}\right)_{2}$ and $2 \mathrm{M} \mathrm{Co}\left(\mathrm{NO}_{3}\right)_{2}$ in 50/50 isopropanol/water, dried at $298 \mathrm{~K}$ for $\sim 60 \mathrm{~s}$ and then heat treated at $648 \mathrm{~K}$ in air for $10 \mathrm{~min}$ to form the $\mathrm{NiCo}_{2} \mathrm{O}_{4}$ spinel. The dip, dry and heat cycle was repeated 3 times before the sample was calcined at $648 \mathrm{~K}$ for $3 \mathrm{hrs}$. The procedure 
always had the two stages but a number of parameters within it (eg. ratio of Ni:PTFE, loading, dipping solution, thermal treatment) were varied as set out in the results section. For comparison, some GDEs were prepared where $\mathrm{NiCo}_{2} \mathrm{O}_{4}$ spinel powder was used instead of $\mathrm{Ni}$ powder; these were fabricated in a single stage.

Figure 1 reports SEM images of the $\mathrm{NiCO}_{2} \mathrm{O}_{4}$ coated Ni powder/PTFE GDEs. Figure 1(a) shows the uniform surface of the electrodes exposed to the electrolyte when mounted in the cell; SEM images of the gas side clearly show that foam structure is maintained. Figure 1(b) shows a cross section with a dense layer and a rather open layer for the gas side. Figure 2 shows high resolution SEM images of the surface of the $\mathrm{NiCo}_{2} \mathrm{O}_{4}$ coated Ni powder/PTFE GDE along with the Ni/PTFE layer before deposition of the spinel catalyst. It can be seen that before the coating with catalyst, the surface consists of small angular particles of nickel while after coating, rather unstructured patches of the spinel catalyst are dispersed over the surface.

\subsection{Electrochemical Experiments}

Electrochemical experiments were carried out in a water jacketed glass cell (volume 200 $\mathrm{cm}^{3}$ ) with a GDE, a platinum gauze counter electrode and a laboratory prepared $\mathrm{Hg} / \mathrm{HgO}$ reference electrode placed inside a compartment with a Luggin capillary. The GDE discs (diameter $12 \mathrm{~mm}$ ) were mounted inside a PTFE holder with the $\mathrm{NiCo}_{2} \mathrm{O}_{4}$ coated $\mathrm{Ni}$ powder/PTFE layer adjacent to the electrolyte. The area of the GDE exposed to the electrolyte was $0.5 \mathrm{~cm}^{2}$ and electrical contact was made with a nickel mesh and wire on the gas side. A Grant TC120 recirculator with 5 litre reservoir maintained the electrolyte temperature at $333 \mathrm{~K} . \mathrm{O}_{2}$ was passed to the rear of the GDE with a feed rate of $200 \mathrm{~cm}^{3} \mathrm{~min}^{-1}$, controlled via a flow meter. The electrolyte was $8 \mathrm{M} \mathrm{NaOH}$ at $333 \mathrm{~K}$. Current cycling was carried out under galvanostatic control at current densities in the range $10-100 \mathrm{~mA} \mathrm{~cm}^{-2}$. All current densities are based on the geometric area of the electrode $\left(0.5 \mathrm{~cm}^{2}\right)$ exposed to the electrolyte and gas compartments. Electrochemical measurements were carried using an Autolab potentiostat/galvanostat, PGSTAT128N.

\subsection{Other Instrumentation}

SEM images and EDAX data were obtained on a JEOL JSM 6500F Scanning Electron Microscope. TEM images were collected on a JEM-2100 microscope in bright field mode; samples were dusted onto 400 mesh copper grids (Aldrich). Powder XRD were recorded on an Agilent Supernova XRD Diffractometer with a Mo k $\alpha$ source. A small sample of powder was prepared in a $0.3 \mathrm{~mm}$ diameter glass capillary. Theoretical $\mathrm{NiCo}_{2} \mathrm{O}_{4}$ pattern produced using Crystal Maker v8.7.2 
and Crystal Diffract v5.2. Surface areas were determined with a Micromeritics - Gemini BET Instrument using nitrogen as the gas.

\section{$3 \quad$ Results and Discussion}

Initially, the performance of a $\mathrm{NiCo}_{2} \mathrm{O}_{4}$ coated $\mathrm{Ni}$ powder/PTFE GDE and a $\mathrm{NiCo}_{2} \mathrm{O}_{4}$ powder/PTFE GDE during both $\mathrm{O}_{2}$ reduction and $\mathrm{O}_{2}$ evolution were compared in $8 \mathrm{M} \mathrm{NaOH}$ and at a temperature of $333 \mathrm{~K}$. In these experiments, a cathodic current is passed for 30 minutes, then an anodic current for the same period (corresponding to discharging and charging of a battery respectively) and the potential of the GDEs vs a $\mathrm{Hg} / \mathrm{HgO}$ reference electrode are recorded. Figure 3 shows the responses for three current densities. It can be seen that following a short initial period, the potentials are always constant and that the difference in potentials for $\mathrm{O}_{2}$ reduction and evolution increase slightly with current density due to increases in the overpotentials and IR drops. Clearly, there are significant overpotentials associated with both $\mathrm{O}_{2}$ reduction and evolution but the differences in potential between the two reactions, $710 \mathrm{mV}$ and $770 \mathrm{mV}$ for the spinel powder and spinel coated $\mathrm{Ni}$ electrodes respectively at $50 \mathrm{~mA} \mathrm{~cm}^{-2}$, compares favourably with all other catalysts tested and this included a number containing precious metals. It can also be seen that the spinel powder electrodes performed slightly better than the spinel coated Ni GDEs but the difference in performance decreased with increasing current density. But the improvement in performance is achieved at the cost of a very heavy loading of spinel catalyst. Hence, electrodes were prepared with mixtures of nickel metal and spinel powders, followed by dip coating and some results are summarised in table 1. The overpotentials for both $\mathrm{O}_{2}$ reduction and evolution decrease as the spinel content is increased but even $10 \%$ spinel corresponds to a high weight loading of catalyst. Hence, since a significant improvement in performance requires a high loading of spinel powder, the electrodes based on Ni powder have been developed further.

It was shown in an earlier communication [7] that $\mathrm{O}_{2}$ evolution and reduction occur with the transition metals ions within the spinel structure in different oxidation states. This leads to a different open circuit potential following reduction or evolution and to the initial periods before the potential takes up a constant value when the electrode is switched between $\mathrm{O}_{2}$ evolution and reduction (see figure 3). The first reaction to occur is always the change in oxidation state of the metals ions within the spinel before the $\mathrm{O}_{2}$ reactions take over when the spinel is full oxidised/reduced. As expected the initial period is most pronounced with higher spinel content (powder vs coating) and lower current density. 
Table 1 also reports the behaviour of a Ni powder/PTFE GDE that has not been subjected to the second stage of the fabrication procedure, ie. dip coating and heat treatment to form a spinel coating. In particular, the resulting GDE is a very bad electrode for $\mathrm{O}_{2}$ reduction and, indeed, in the steady state with a cathodic current, the potential takes up a potential close to $-1000 \mathrm{mV}$ vs $\mathrm{Hg} / \mathrm{HgO}$ and the major reaction occurring is $\mathrm{H}_{2}$ evolution. The $\mathrm{NiCo}_{2} \mathrm{O}_{4}$ layer is the catalyst for the $\mathrm{O}_{2}$ reactions and a key component of the bifunctional GDEs.

The conditions for the formation of the spinel coating in the GDEs were investigated. In all cases, the thermal treatment was carried out at $648 \mathrm{~K}$ for 3 hours since $\mathrm{NiCo}_{2} \mathrm{O}_{4}$ is formed rapidly at this temperature and thermogravimetric analysis showed that PTFE underwent decomposition above $670 \mathrm{~K}$. Indeed, the fact that the spinel is formed at a relatively low temperature where the PTFE is chemically stable is a key factor in the choice of the catalyst for these GDEs. The temperature of $648 \mathrm{~K}$ is, however, certainly sufficient to cause the polymer to flow and the heat treatment is likely to be influential in determining the final structure of the GDEs. Firstly, GDEs were prepared using several different nickel and cobalt salts dissolved in water and the results are presented in table 2. The significant difference is in the potential for the reduction reaction since the nickel foam substrate is already a reasonable catalyst for $\mathrm{O}_{2}$ evolution. The temperature of the thermal treatment is insufficient to convert the chloride material to the spinel structure but both the acetates and the nitrates are converted to effective catalyst and the latter were used in all later preparations. The total concentration of the Ni/Co nitrate solution in the dip solution was varied $(0.75,1.5$ and $3 \mathrm{M}$ ) while maintaining the $\mathrm{Ni}$ :Co ratio at $1: 2$ and the overpotentials for both $\mathrm{O}_{2}$ reduction and evolution were reduced using the more concentrated; GDEs prepared with the $3 \mathrm{M}$ solution gave a potential gap between $\mathrm{O}_{2}$ reduction and evolution $\sim 100 \mathrm{mV}$ less than GDEs prepared with the $0.75 \mathrm{M}$ solution with a current density of $50 \mathrm{~mA} \mathrm{~cm}{ }^{-2}$. Finally, the influence of the solvent for the dip solution was studied. Solutions of the Ni/Co nitrates were prepared in 1:1 mixtures of water with five alcohols and the alcohols led to small improvements in the performance of the GDEs probably resulting from changes in surface tension and/or viscosity leading to differences in the ability of the dip solution to diffuse into the Ni powder/PTFE layer. The 1:1 isopropanol:water dip solution led to a GDE with the smallest difference in potential between $\mathrm{O}_{2}$ reduction and evolution. With the 1:1 isopropanol:water solution containing $3 \mathrm{M} \mathrm{Ni} / \mathrm{Co}$ nitrates, three dip/thermal treatment cycles 
were sufficient to give the optimum GDE performance when the spinel catalyst loading was estimated by weight change as $\sim 3 \mathrm{mg} \mathrm{cm}^{-2}$.

The ratio of PTFE: nickel powder is a key factor in determining the performance of the GDEs both in terms of the potentials for $\mathrm{O}_{2}$ reduction and evolution and the stability of this performance during long term charge/discharge cycling. The PTFE is required as a binder but it also controls the ingress of the aqueous electrolyte into the PTFE/nickel powder structure and hence access of both the electrolyte and oxygen gas phases to the catalyst sites. Too low PTFE content will lead to an excess of aqueous electrolyte penetration denying access to the gas phase and eventual flooding with passage of electrolyte through to the gas phase. Too high PTFE content leads to a failure to allow access of the aqueous electrolyte to the catalyst site and even passage of the gas through to the electrolyte. It may also add substantially to the resistance of the layer. GDEs with PTFE contents between $12 \%$ and $27 \%$ were subjected to tests for $\mathrm{O}_{2}$ reduction and evolution at $50 \mathrm{~mA} \mathrm{~cm}$. All the GDEs supported both reactions with not dissimilar initial potentials for both $\mathrm{O}_{2}$ reduction and evolution, see figure 4; indeed, there was a small trend for the difference in the potentials for the two reactions decreasing with lower PTFE content. The electrodes with low PTFE contents, however sometimes flooded and on cycling between $\mathrm{O}_{2}$ reduction and evolution, the difference in potentials increased after only a few cycles. Hence, $23 \%$ PTFE (ratio of Ni powder:PTFE $=10: 3$ ) was selected as a safe option for long term stability without a large increase in the potential difference.

Further sets of experiments were carried out to define the influence of the weight loading of Ni powder/PTFE (10:3) paste and the pressure exerted during the manufacture of the GDEs. In the first set the loading was varied over the range $120-280 \mathrm{mg} \mathrm{cm}^{-2}$ of wet paste. The lowest loading suffered from electrolyte leakage through to the gas side but over the range $140-280 \mathrm{mg} \mathrm{cm}^{-2}$ good responses were obtained with a small trend to higher overpotentials with thickening of the Ni powder/PTFE layer. Electrodes were also pressed with compressions in the range $0.5-2.5 \mathrm{kN} \mathrm{cm}^{-2}$; the lowest pressure was insufficient to create a compact electrodes and leakage was an immediate problem, but above $1 \mathrm{kN} \mathrm{cm}^{-2}$ the electrodes gave good data with a slight tendency for the overpotentials to increase with increasing pressure (see figure 6), probably due to a decrease in size of the gas pores. Electrodes prepared with a loading of $200 \mathrm{mg} \mathrm{cm}^{-2}$ wet paste (approximately $90 \mathrm{mg} \mathrm{cm}^{-2} \mathrm{Ni}+$ $30 \mathrm{mg} \mathrm{cm}^{-2}$ PTFE) and a compression of $1.5 \mathrm{kN} \mathrm{cm}^{-2}$ have given reproducible behaviour and good long term stability and have been used for further electrode development. 
Several electrodes were further tested by cycling 10 times between 30 minutes $\mathrm{O}_{2}$ reduction and 30 minutes $\mathrm{O}_{2}$ evolution using current densities of $20 \mathrm{~mA} \mathrm{~cm}{ }^{-2}$ or $50 \mathrm{~mA} \mathrm{~cm}$. In general, stable potentials were observed each cycle following initial periods where the spinel coating is oxidised/reduced and commonly the potentials for $\mathrm{O}_{2}$ reduction and $\mathrm{O}_{2}$ evolution were unchanged during the 10 cycles. Some electrodes, eg. those with a low PTFE content, showed a small negative shift in the potential during $\mathrm{O}_{2}$ reduction over the 10 cycles and this was taken as an indication of ingress of aqueous electrolyte into the GDE structure reducing the access of $\mathrm{O}_{2}$ gas to the catalyst sites. Some such tests were also carried out replacing the oxygen feed by an air feed. Again, stable potentials were established but the potential for oxygen reduction shifted negative. At $50 \mathrm{~mA} \mathrm{~cm}{ }^{-2}$, the negative shift was $70 \mathrm{mV}$.

Although the glass cell and auxiliary equipment used in this programme is not designed for testing over many days, some longer term experiments have been carried out. Figure 7 shows the potential vs time responses for cycles $1-10$ and $40-50$ for an experiment carried out with a current density of $50 \mathrm{~mA} \mathrm{~cm}^{-2}$ and fabricated using the precise conditions of the recipe in the Experimental Section. It can be seen that there is a slight trend to an improvement in performance with cycling but the changes in the potentials over the 50 cycles are small. The average separation of the potentials for $\mathrm{O}_{2}$ reduction and evolution during the 50 cycles is $800 \mathrm{mV}$ equivalent to a voltage efficiency for a $\mathrm{Zn} /$ air battery of $60 \%$. If fact, the experiment was continued for 100 cycles but beyond 50 cycles, the potential for $\mathrm{O}_{2}$ reduction became more negative with time, reaching $-440 \mathrm{mV}$ after 100 cycles. - In the ideal situation, during $\mathrm{O}_{2}$ evolution, the gas would be released to the back of the electrode into the gas phase and away from the interelectrode gap. While it cannot be quantified with the present equipment, it is clear by visual observation that almost no $\mathrm{O}_{2}$ gas is evolved into the electrolyte and hence that most is, indeed released to the back of the GDE.

Larger GDEs have been fabricated. Figure 8 is a photograph of a $50 \mathrm{~mm} \times 50 \mathrm{~mm}$ electrode made from the thinner $\mathrm{Ni}$ foam for a flow cell. The electrode is flat with a uniform black appearance and its thickness was measure as $0.75 \mathrm{~mm}$. It is robust and can be extensively handled without damage making it well suited to incorporation into flow cells.

\section{Conclusions}

Gas diffusion electrodes without carbon components have been satisfactorily fabricated and tested as a bifunctional electrode for $\mathrm{O}_{2}$ reduction/evolution. The electrodes can operate at $100 \mathrm{~mA} \mathrm{~cm}^{-2}$ and cycle well at $50 \mathrm{~mA} \mathrm{~cm}^{-2}$ and the performance may well be 
adequate for practical secondary $\mathrm{Zn} /$ air batteries. These current densities are, however, low compared to those possible with MEA type GDEs with carbon components for fuel cells ( > $1000 \mathrm{~mA} \mathrm{~cm}^{-2}$ ) suggesting that further enhancement of the $\mathrm{O}_{2}$ flux is still possible. Moreover, the overpotentials observed for both $\mathrm{O}_{2}$ reduction and $\mathrm{O}_{2}$ evolution, while comparable with those reported for other catalysts, are not as low as one would like. The choice of $\mathrm{NiCo}_{2} \mathrm{O}_{4}$ spinel as the catalyst results from the fact that for this method of fabrication of the GDEs, the catalyst layer must be prepared at a temperature below that where the PTFE decomposes.

\section{Acknowledgement}

Financial support by the European Commission (Theme 2010.7.3.1) Energy Storage Systems for Power Distribution Networks, Grant Agreement No. 256759, is gratefully acknowledged.

\section{References}

1. P. Leung, X. Li, C. Ponce de Leon, L. Berlouis, C.T.J. Low and F.C. Walsh, Progress in Redox Flow Batteries, Remaining Challenges and Their Applications in Energy Storage, RSC Advances, (2012) 1-32.

2. Z. Yang, J. Zhang, M.C.W.Kintner-Meyer, X. Lu, J.P. Lemmon and J. Lui, Electrochemical Energy Storage for Green Grid, Chem. Rev., 111 (2011) 3577-3613.

3. M. Skyllas-Kazacos, M.H. Chakrabarti, S.A. Hajimolana, F.S. Mjalli and M. Saleem, Progress in Flow Battery Research and Development, J. Electrochem. Soc., 158 (2011) R55-R79.

4. R.P. Hamlen, T.B. Atwater, in: D. Linden, T.B. Reddy (Eds.), Handbook of Batteries, third ed., McGraw-Hill, New York, 2002, pp. 38.1-38.53.

5. F. Cheng and J. Chen, Metal Air Batteries: From Oxygen Reduction Electrochemistry to Cathode Catalysts, Chem. Soc. Rev., 41 (2012) 2172-2192.

6. J. Pan, L. Ji, Y. Sun, P. Wan, J. Cheng, Y. Yang and M. Fan, Preliminary Study of Alkaline Single Flowing Zn--O Battery, Electrochem. Commun., 11 (2009) 2191-2194.

7. X. Li, D. Pletcher, A.E. Russell, F.C. Walsh, R.G.A. Wills, S.F. Gorman, S.W. Price and S.J. Thompson, A Novel Bifunctional Oxygen GDE for Alkaline Secondary Batteries, Electrochem. Commun., 34 (2013) 228. 
8. K. Kinoshita, Electrochemical Oxygen Technology, John Wiley \& Sons Inc. 1992.

9. L. Jörissen, Bifunctional Oxygen/Air Electrodes, J. Power Sources, 155 (2006) 23-32.

10. M.R. Tarasevich, B.N. Efremov, in: S. Trasatti (Ed.), Electrodes of Conductive Metallic Oxides, Elsevier Scientific Publishing Company, 1980, pp. 221-59.

11. P. Rasiyah, A.C.C. Tsueng, D.B. Hibbert, A Mechanistic Study of Oxygen Evolution on $\mathrm{NiCo}_{2} \mathrm{O}_{4}$. 1. Formation of Higher Oxides, J. Electrochem. Soc., 129 (1982) 1724-1727.

12. P. Rasiyah and A.C.C. Tseung, A Mechanistic Study of Oxygen Evolution on $\mathrm{NiCo}_{2} \mathrm{O}_{4}$. 2. Electrochemical Kinetics, J. Electrochem. Soc., 130 (1983) 2384-2386.

13. P.N. Ross, Proceedings of the $10^{\text {th }}$ Annual Battery Conference on Applications and Advances, 1995, pp. 131.

14. X. Li, F.C. Walsh and D. Pletcher, A Comparison of Nickel Based Electrocatalysts for Oxygen Evolution in a Zero Gap Water Electrolyser with a Hydroxide Conducting Membrane, Phys. Chem. Chem. Phys. 13 (2011) 1162-1167.

15. S.W. Price, S.J. Thompson, D. Pletcher and A.E. Russell, to be published.

16. N. Staud, and P.N. Ross, The Corrosion of Carbon Black Anodes in Alkaline Electrolyte, Part II. Acetylene Black and the Effect of Oxygen Evolution Catalysts on Corrosion, $J$. Electrochem. Soc., 133 (1986) 1079-1084.

17. P.N. Ross and M. Sattler, The Corrosion of Carbon Black Anodes in Alkaline Electrolyte, Part III. The Effect of Graphitization on the Corrosion Resistance of Furnace Blacks, $J$. Electrochem. Soc., 135 (1988) 1464-1470.

18. N. Staud, H. Sokol and P.N. Ross, The Corrosion of Carbon Black Anodes in Alkaline Electrolyte, Part IV. Current Efficiencies for Oxygen Evolution from Oxide-Impregnated Graphitized Furnace Blacks, J. Electrochem. Soc., 136 (1989) 3570-3576.

19. S. Müller, F. Holzer, H. Arai and O. Haas, A Studyof Carbon-Catalyst Interaction in Bifunctional Air Electrodes for Zinc-Air Batteries, J. New Mater. Electrochem. Systems, 2 (1999) 227-232. 


\begin{tabular}{|l|c|c|c|c|}
\hline \multicolumn{1}{|c|}{ Sample } & $\begin{array}{c}\text { Dip } \\
\text { Coated }\end{array}$ & $\begin{array}{c}\text { Reduction E/ mV } \\
\text { vs Hg/HgO }\end{array}$ & $\begin{array}{c}\text { Evolution E/ mV } \\
\text { vs Hg/HgO }\end{array}$ & $\begin{array}{c}\text { ORR-OER } \\
\text { Gap, } \boldsymbol{\Delta E} / \mathbf{m V}\end{array}$ \\
\hline $100 \% \mathrm{Ni}$ & $\mathrm{No}$ & $\mathrm{H}_{2}$ evolution & $* * *$ & - \\
\hline $100 \% \mathrm{Ni}$ & Yes & -208 & 658 & 866 \\
\hline $90 \% \mathrm{Ni} / 10 \% \mathrm{NiCo}_{2} \mathrm{O}_{4}$ & Yes & -183 & 628 & 811 \\
\hline $50 \% \mathrm{Ni} / 50 \% \mathrm{NiCo}_{2} \mathrm{O}_{4}$ & Yes & -166 & 589 & 755 \\
\hline $100 \% \mathrm{NiCo}_{2} \mathrm{O}_{4}$ & Yes & -138 & 532 & 670 \\
\hline
\end{tabular}

Table 1 Potentials for $\mathrm{O}_{2}$ reduction and evolution at $50 \mathrm{~mA} \mathrm{~cm}^{-2}$ for GDEs prepared with $\mathrm{Ni}$ powder (dip coated with $\mathrm{NiCo}_{2} \mathrm{O}_{4}$ and also without dip coating), spinel and mixtures of nickel and spinels (dip coated). GDEs were 10:3 Ni powder:PTFE and the spinel coating was formed at $648 \mathrm{~K}$ for 3 hours. $8 \mathrm{M} \mathrm{NaOH} .333 \mathrm{~K}$.

\begin{tabular}{|c|c|c|c|}
\hline Salt & $\begin{array}{c}\text { Reduction E/ mV vs } \\
\mathbf{H g} / \mathbf{H g O}\end{array}$ & $\begin{array}{c}\text { Evolution E/ mV vs } \\
\mathbf{H g} / \mathbf{H g O}\end{array}$ & $\begin{array}{c}\text { ORR-OER Gap, } \\
\boldsymbol{\Delta} \boldsymbol{E} / \mathbf{m V}\end{array}$ \\
\hline Nitrate & -125 & 594 & 719 \\
\hline Sulphate & -378 & 575 & 953 \\
\hline Chloride & -1068 & 526 & 1594 \\
\hline Acetate & -149 & 600 & 749 \\
\hline
\end{tabular}

Table 2 Influence of the anion of the nickel and cobalt salts used in the dip coating solution on performance. GDEs were 10:3 Ni powder:PTFE and the spinel coating was formed at $648 \mathrm{~K}$ for 3 hours. Constant current experiments carried at $20 \mathrm{~mA} \mathrm{~cm}{ }^{-2}$ in $8 \mathrm{MNaOH}$ at $333 \mathrm{~K}$. 


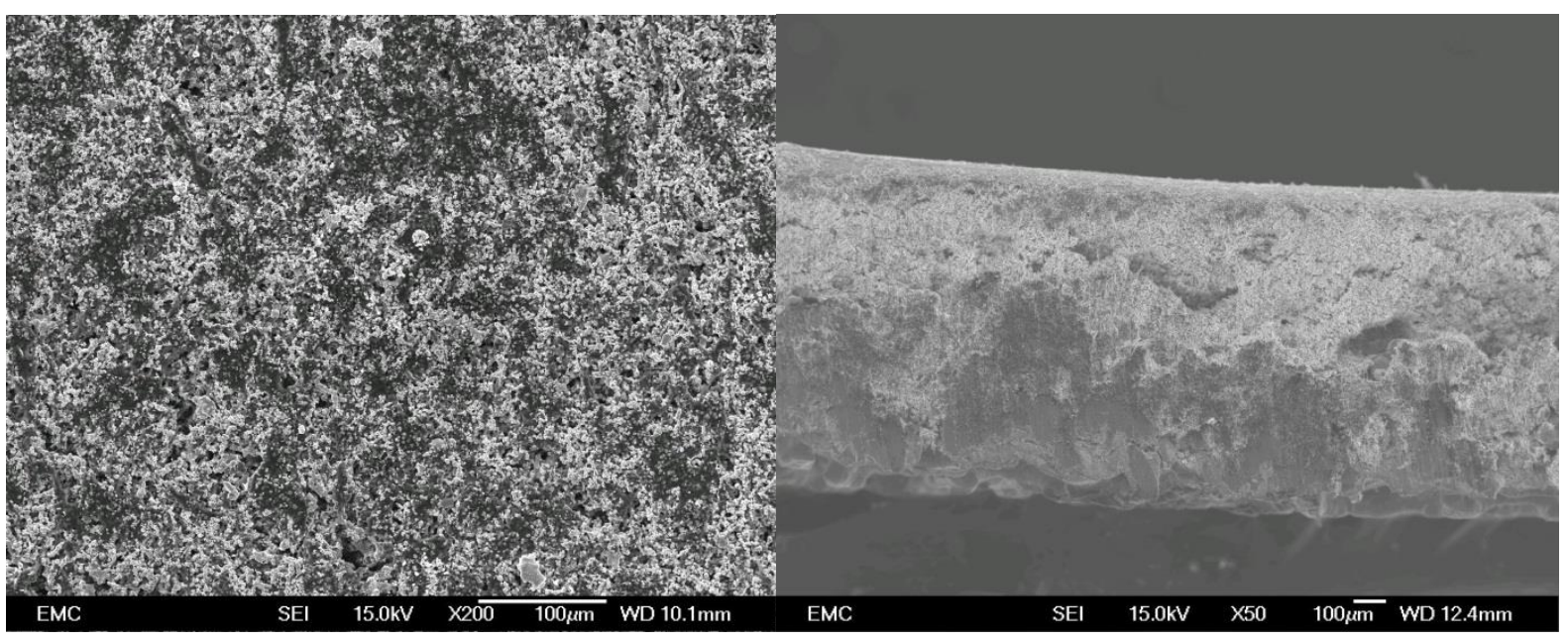

(a)

(b)

Figure 1 SEM images of the bifunctional GDE (a) the surface of the spinel coated Ni powder/PTFE layer and (b) a cross section of the electrode.

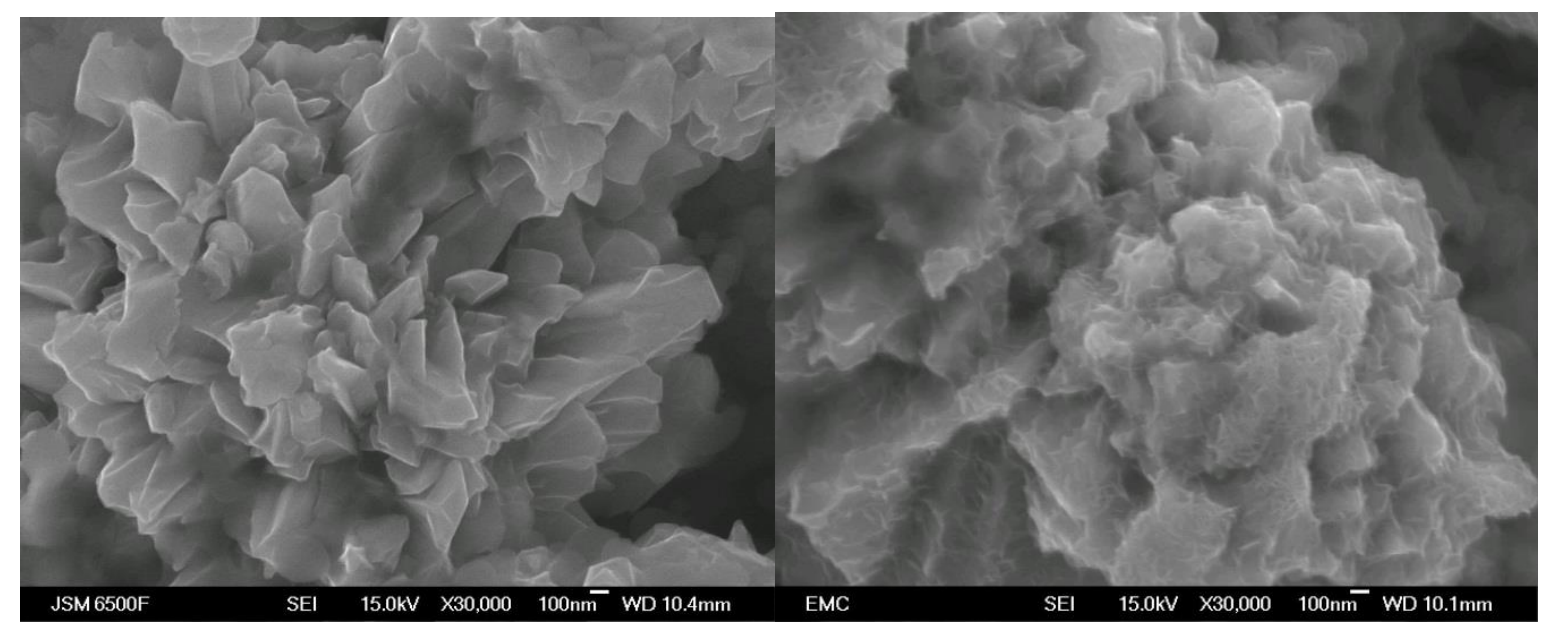

Figure 2 High resolution SEM images of the surfaces of the bifunctional GDE (a) Ni powder/PTFE layer before coating with catalyst (b) $\mathrm{NiCo}_{2} \mathrm{O}_{4}$ coated $\mathrm{Ni}$ powder/PTFE layer. 

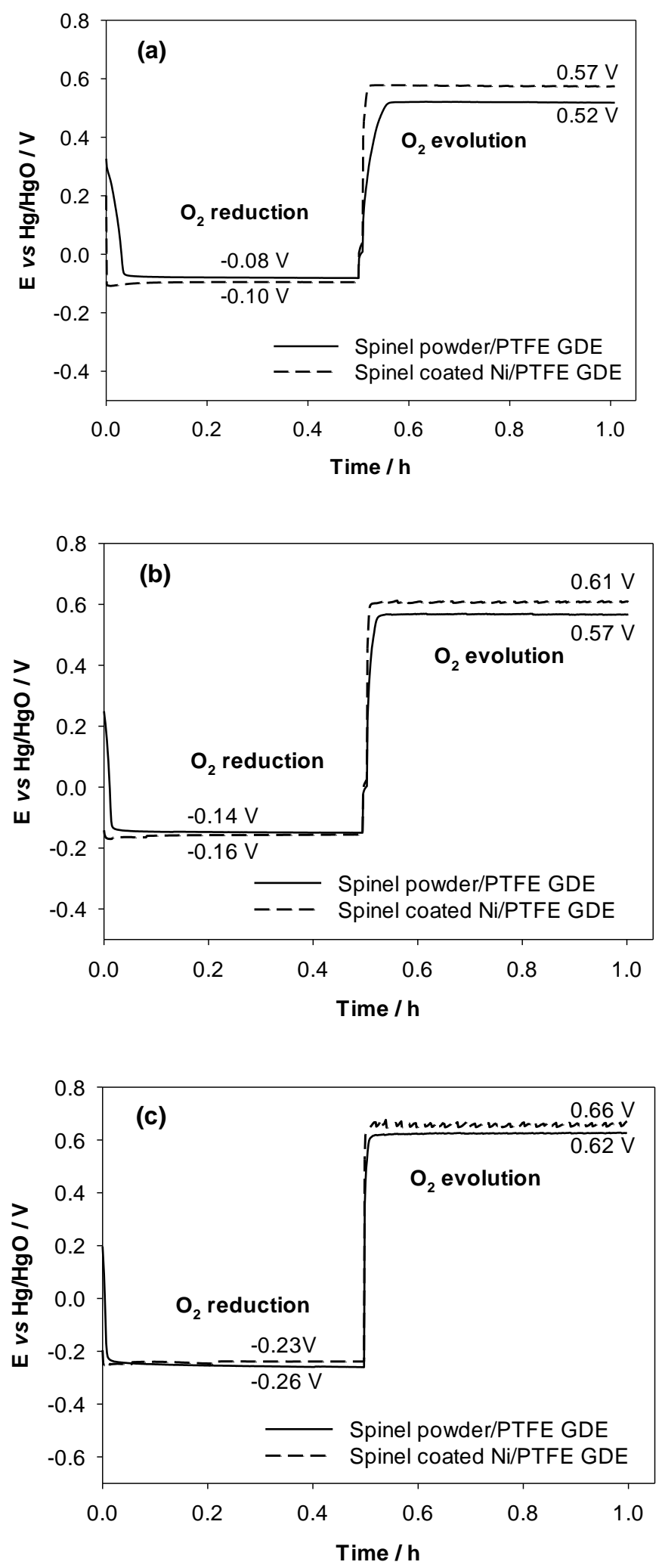

Figure 3 Comparison of the performance of a $\mathrm{NiCo}_{2} \mathrm{O}_{4}$ coated $\mathrm{Ni}$ powder/PTFE GDE and a $\mathrm{NiCo}_{2} \mathrm{O}_{4}$ powder/PTFE GDE during $\mathrm{O}_{2}$ reduction and $\mathrm{O}_{2}$ evolution. Potential vs

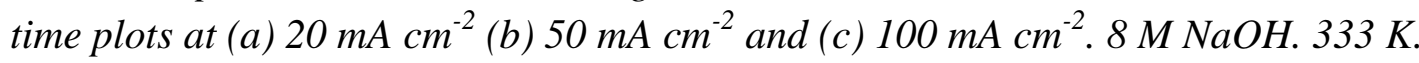




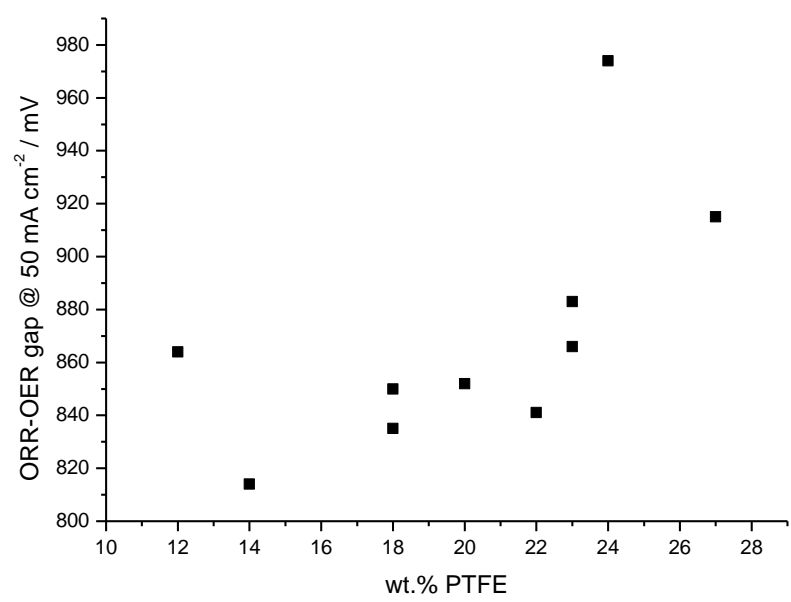

Figure 4 The influence of the PTFE content on the performance of $\mathrm{NiCo}_{2} \mathrm{O}_{4}$ coated $\mathrm{Ni}$ powder/PTFE GDEs for $\mathrm{O}_{2}$ reduction and $\mathrm{O}_{2}$ evolution at $50 \mathrm{~mA} \mathrm{~cm}^{-2}$ - difference in potentials for $\mathrm{O}_{2}$ reduction and $\mathrm{O}_{2}$ evolution vs \% PTFE. $8 \mathrm{M} \mathrm{NaOH} .333 \mathrm{~K}$.

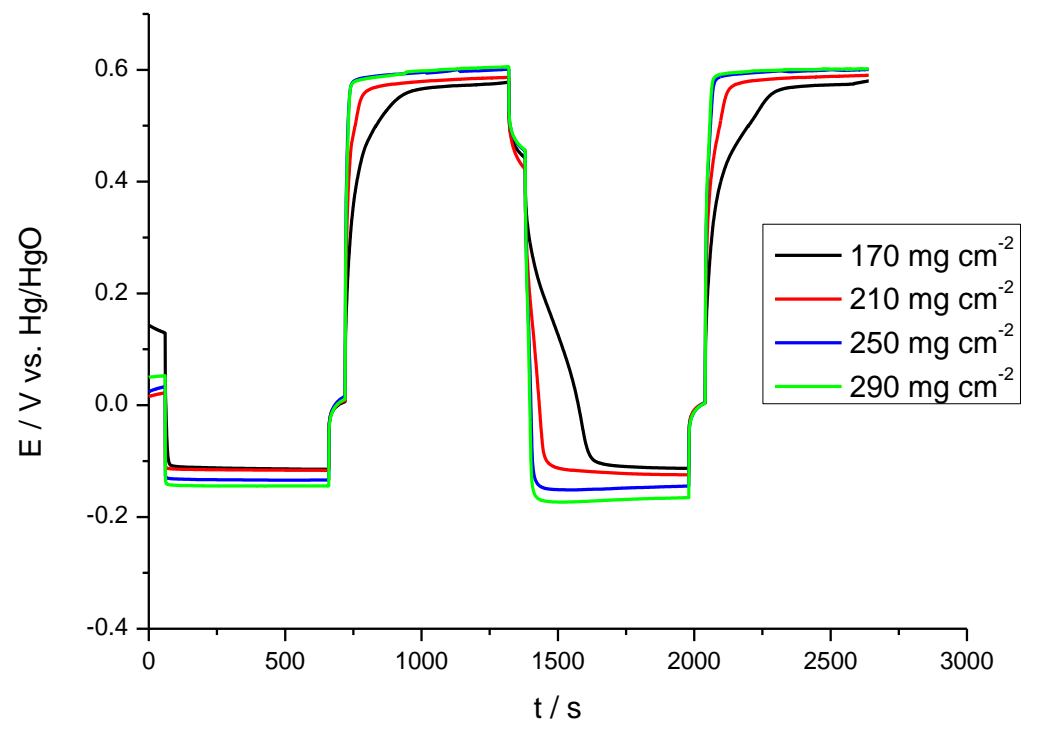

Figure 5 Plots of potential versus time for $\mathrm{NiCO}_{2} \mathrm{O}_{4}$ coated $\mathrm{Ni}$ powder/PTFE GDEs during $\mathrm{O}_{2}$ reduction and $\mathrm{O}_{2}$ evolution at $20 \mathrm{~mA} \mathrm{~cm}$ as a function of the Ni powder/PTFE (10:3) paste. $8 \mathrm{M} \mathrm{NaOH} .333 \mathrm{~K}$. 


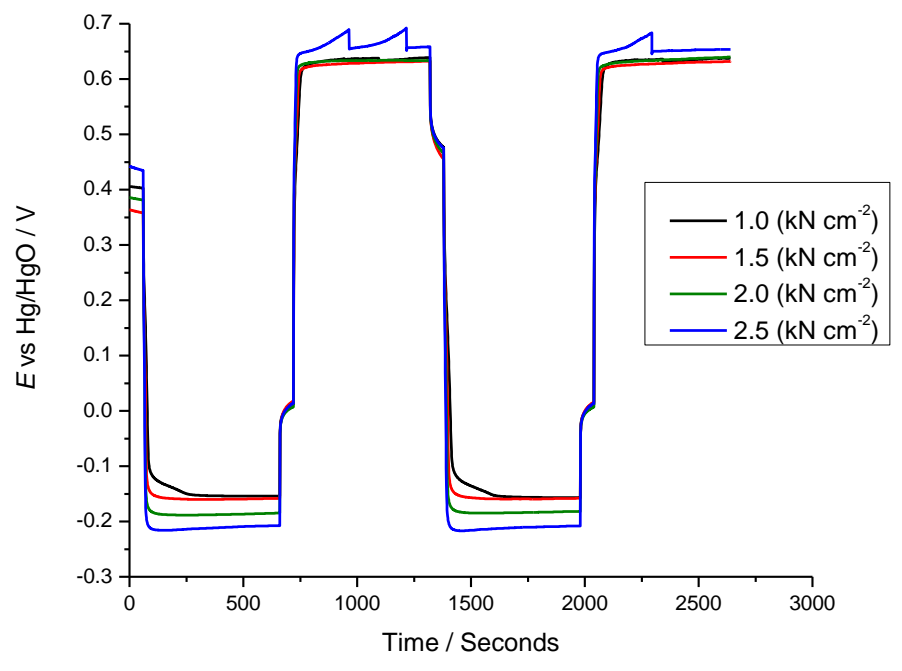

Figure 6 Influence of compression during $\mathrm{NiCO}_{2} \mathrm{O}_{4}$ coated $\mathrm{Ni}$ powder/PTFE GDE preparation on $\mathrm{O}_{2}$ reduction, $\mathrm{O}_{2}$ evolution cycling at $50 \mathrm{~mA} \mathrm{~cm}^{-2}$. $8 \mathrm{M} \mathrm{NaOH}, 333 \mathrm{~K}, 200 \mathrm{ml} \mathrm{min}^{-1} \mathrm{O}_{2}$, 


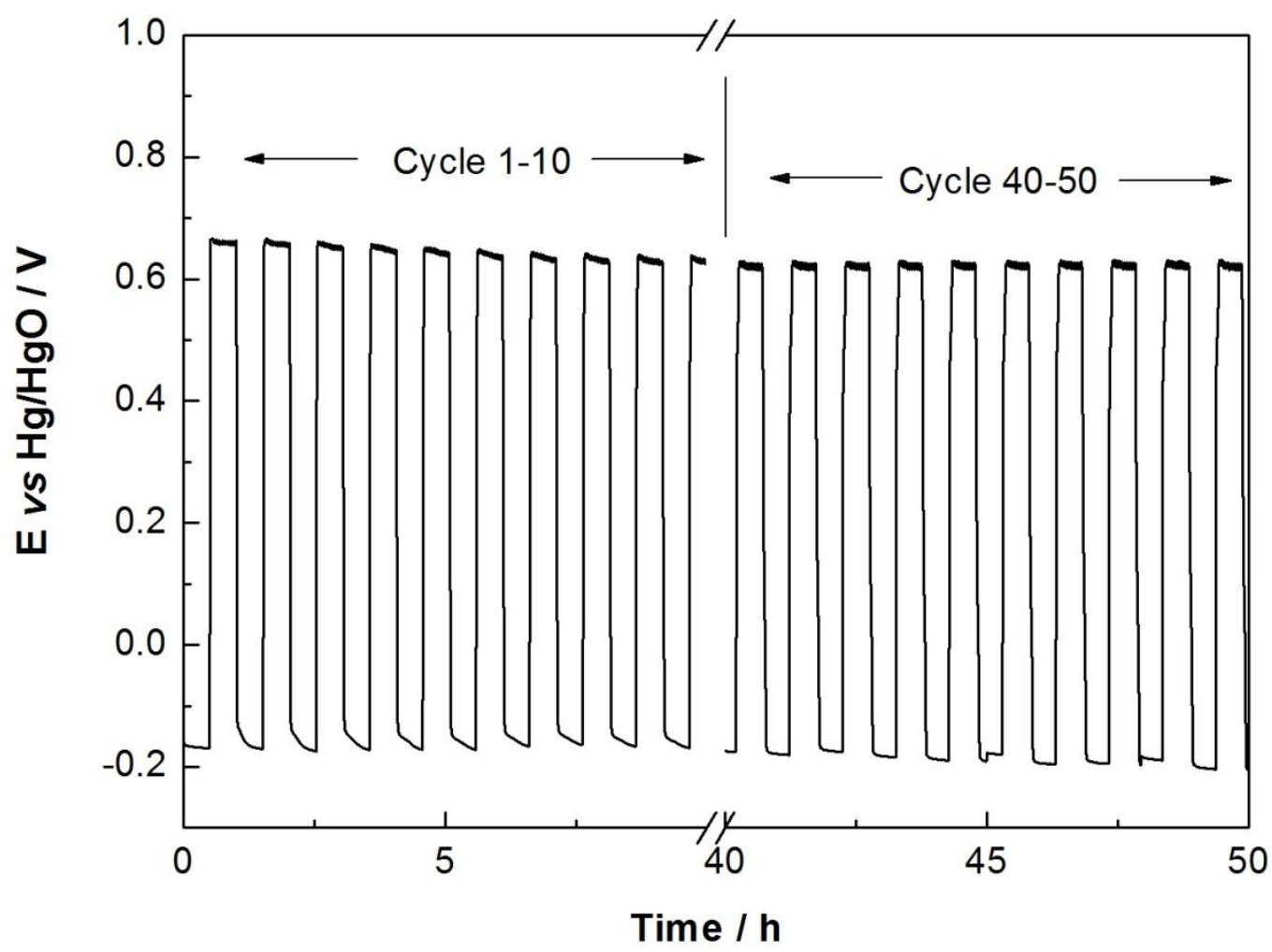

Figure 7 Potential vs time responses during current density cycling of a $\mathrm{NiCo}_{2} \mathrm{O}_{4}$ coated Ni powder/PTFE GDE at $50 \mathrm{~mA} \mathrm{~cm}^{-2}$ in $8 \mathrm{M} \mathrm{NaOH}$ at $333 \mathrm{~K}$. Oxygen feed rate: $200 \mathrm{~cm}^{3} \mathrm{~min}^{-1}$. Shown are 1-10 and 40-50 cycles.

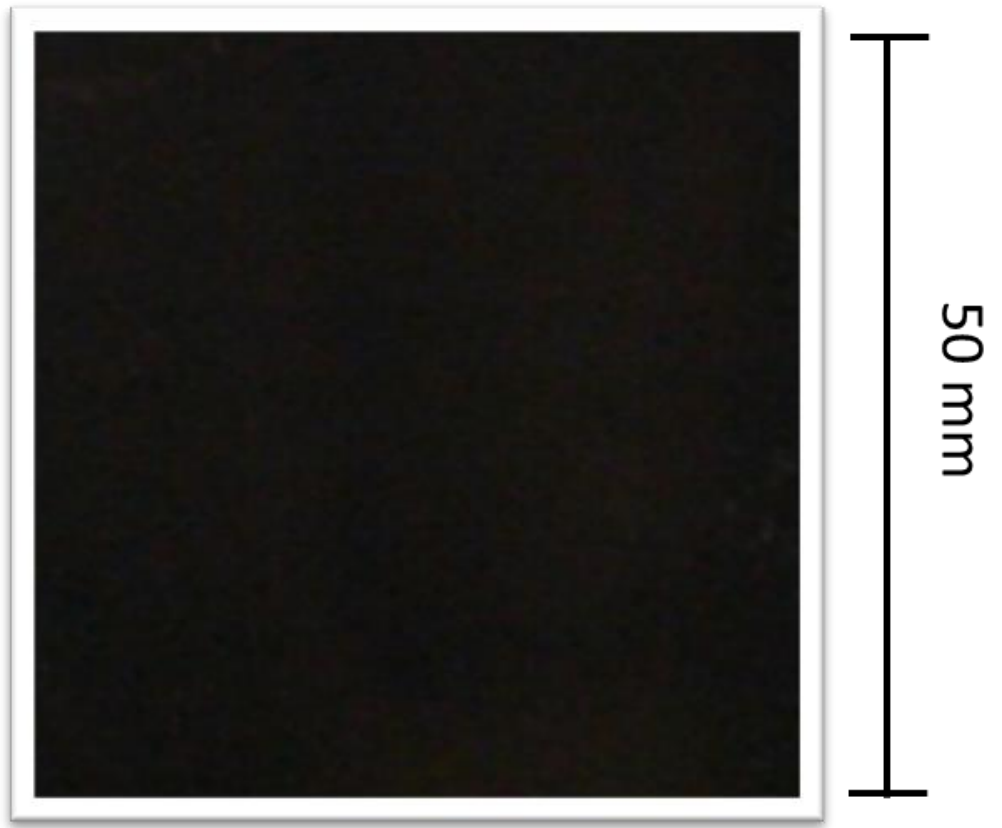

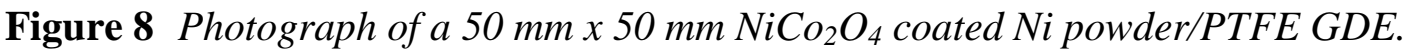

